\title{
The Bacteriological Profile of Neonatal Sepsis in Preterm Babies in Tertiary Medical College and Hospital
}

Dr. Md. Shafiqul Islam*, Dr. Md. Jamshed Alam, Dr. Shah Muhammad Masuduzzaman, Dr. Mohammad Shawkat Hossain Khan, Dr. Mohammad Forhad Hossain, Dr. Mohammad Jahangir Alarm, Dr. Nazmul Hossain

Assistant Professor, Department of Pediatrics, Sheikh Hasina Medical College, Tangail, Bangladesh

DOI: $10.36347 /$ sjams.2020.v08i06.015

| Received: 19.05.2020 | Accepted: 27.05.2020 | Published: 18.06.2020

*Corresponding author: Dr. Md. Shafiqul Islam

Abstract

Original Research Article

Objective: In this study our main goal is to evaluate bacteriological profile of neonatal sepsis in preterm babies of tertiary medical college and hospital. Method: this was a prospective observational and experimental study was carried out at Sir Salimullah Medical College and Mitford Hospital, Dhaka from July 2010 to October 2011 among 80 preterm babies. Results: The mean ( \pm SD) weight of the babies was $1713.8( \pm 436.0)$ gm with a range of 500-2750 gm, 4(5.0\%) babies were extreme preterm (gestational age <28 weeks), 12(15.0\%) babies were very preterm (gestational age 28 to $<32$ weeks) and 64(80.0\%) babies were preterm (gestational age 32 to <37 weeks). Ampicillin $71(88.8 \%)$ andgentamicin71(88.8\%) were used in most of the cases, followed by ceftazidime35(43.8) and amikacin in $35(43.8 \%)$ cases, meropenem in $8(10.0 \%)$ cases, ciprofloxacin in $7(8.8 \%)$ cases, metronidazole in $11(13.8 \%)$ cases. Among the organisms, Acinatobacter were present in 2 (2.5\%) patient, Pseudomonas were present in 2(2.5\%), CONS were present in $2(2.5 \%)$, Citrobacter in $1(1.3 \%)$ patient. Conclusion: From our study we can say that Acinatobacter, Pseudomonas and CONS were the most common isolate in our study. Early diagnosis and therapy are essential for the prevention of morbidity and mortality of neonatal sepsis in the neonatal intensive care unit.

Keywords: Bacteriological profile, neonatal sepsis, preterm babies.

Copyright @ 2020: This is an open-access article distributed under the terms of the Creative Commons Attribution license which permits unrestricted use, distribution, and reproduction in any medium for non-commercial use (NonCommercial, or CC-BY-NC) provided the original author and source are credited.

\section{INTRODUCTION}

Neonatal sepsis is defined as a clinical syndrome of bacteremia with systemic signs and symptoms of infection in the first 4 weeks of life [1]. Septicemia occurs in $2.3 \%$ of intramural live births. Over $40 \%$ of the under-5 deaths globally occur in the neonatal period [2]. The World Health Organization estimates that $>1$ million neonatal deaths worldwide annually are caused by severe infections, and $\sim 1$ million deaths are due to neonatal sepsis or pneumonia alone [3]. Morbidity of neonatal sepsis differs significantly from country to country. The incidence of neonatal sepsis varies from 1 to 5 cases per 1,000 live births in developed countries, but increases in developing countries, varying from 49 to 170 per 1,000 [4]. Early empirical antibiotic treatment of neonates suspected of having septicemia is the standard practice. Nonetheless, the dilemma of unnecessary exposure to antibiotics in this vulnerable population remains, creating an environment for emerging bacterial resistance and the potential for poor prognosis [5]. In this study our main goal is to evaluate the bacteriological profile of neonatal sepsis in preterm babies in tertiary medical college and hospital.

\section{OBJECTIVE General Objective}

To assess the bacteriological profile of neonatal sepsis in preterm babies in tertiary medical college and hospital.

Specific Objective

- To detect blood culture findings of the patients.

- To identify specific antibiotics usage according to blood culture sensitivity of the patients.

\section{Methodology}

\section{Types of Study}

- This was a prospective observational and experimental study.

\section{Study place and period}

- This study was conducted at Neonatal Care Unit (NCU) of Sir Salimullah Medical College and Mitford Hospital, Dhaka among 80 preterm babies from July 2010 to October 2011. 


\section{Inclusion Criteria}

- Preterm babies within 72 hours of life admitted in Neonatal Care Unit.

\section{Sampling Technique}

- Patients were selected by purposive sampling.

\section{Study Procedure}

Informed consent was taken from mother, father or any legal attendant of the baby. Information was collected by reviewing the clinical and laboratory findings. Data was collected in a structured questionnaire by the principal investigator. Detail records of gestation, birth-weight, gender and whether the baby transferred after delivery elsewhere were included. Blood culture for bacteria was done in each preterm baby admitted at NCU on admission. Cultures were plated on selective media for isolation of bacteria. Duration of antibiotics, intubation, parenteral nutrition, total central catheter use (umbilical venous catheter, peripherally inserted central catheter), corticosteroids and theophylline were noted and the duration defined in days (with any portion of a day constituting 1 day of treatment). The specimens were placed in a dry medium and taken to the Microbiological Laboratory.

\section{Data Analysis}

- Analysis was performed by using a computer based statistical program SPSS (Statistical Package for Social Sciences) version 12, where descriptive analysis was done for percentage and mean value.

\section{RESULTS}

In Table-1 shows age distribution of the patients where most of the patients belong to 'up to 24 hours', 50(62.5\%). The following table is given below in detail:

Table-1: Age distribution of the patients $(\mathrm{N}=80)$

\begin{tabular}{|l|l|}
\hline Age group & Frequency (\%) \\
\hline Up to 24 hours & $50(62.5 \%)$ \\
\hline $\mathbf{2 4 - 4 8}$ hours & $21(26.3 \%)$ \\
\hline $\mathbf{4 8 - 7 2}$ hours & $9(11.3 \%)$ \\
\hline Total & $80(100 \%)$ \\
\hline
\end{tabular}

In Table-2 shows gender distribution of the patients. Among the patients, 49(61.3\%) babies were male and $31(38.8 \%)$ were female. The following table is given below in detail:

Table-2: Gender distribution of the patients

\begin{tabular}{|l|l|}
\hline Sex of the babies & Cases \\
\cline { 2 - 2 } & Frequency (\%) \\
\hline Male & $49(61.3 \%)$ \\
\hline Female & $31(38.8 \%)$ \\
\hline Total & $80(100 \%)$ \\
\hline
\end{tabular}

In Table-3 shows distribution of the babies according to gestational age where $4(5.0 \%)$ babies were extreme preterm (gestational age <28 weeks), $12(15.0 \%)$ babies were very preterm (gestational age 28 to $<32$ weeks) and $64(80.0 \%)$ babies were preterm (gestational age 32 to $<37$ weeks). The following table is given below in detail:

\section{Table-3: Distribution of the babies according to} gestational age

\begin{tabular}{|l|l|}
\hline Gestational age & Frequency $(\boldsymbol{\%})$ \\
\hline$<28$ weeks & $4(5.0 \%)$ \\
\hline 28 to $<32$ weeks & $12(15.0 \%)$ \\
\hline 32 to $<37$ weeks & $64(80.0 \%)$ \\
\hline Total preterm babies & $80(100 \%)$ \\
\hline
\end{tabular}

Table-4 shows use of antibiotics of the patients where ampicillin $71(88.8 \%)$ and gentamicin71(88.8\%) were used in most of the cases, followed by ceftazidime and amikacin in 35(43.8\%) cases, meropenem in $8(10.0 \%)$ cases, ciprofloxacin in $7(8.8 \%)$ cases, metronidazole in $11(13.8 \%)$ cases. The following table is given below in detail:

Table-4: Use of antibiotics of the patients

\begin{tabular}{|l|l|}
\hline Antibiotics used & Frequency (\%) \\
\hline Ampicillin & $71(88.8 \%)$ \\
\hline Gentamicin & $71(88.8 \%)$ \\
\hline Ceftazidime & $35(43.8 \%)$ \\
\hline Amikacin & $35(43.8 \%)$ \\
\hline Meropenem & $8(10.0 \%)$ \\
\hline Ciprofloxacin & $7(8.8 \%)$ \\
\hline Metronidazole & $11(13.8 \%)$ \\
\hline
\end{tabular}

In Table- 5 shows blood culture findings of the patients. Among the organisms Acinatobacter were present in $2(2.5 \%)$ patients, Pseudomonas were present in $2(2.5 \%)$, CONS were present in $2(2.5 \%)$ Citrobacter in $1(1.3 \%)$ patient. The following table is given below in detail:

Table-5: Blood culture findings

\begin{tabular}{|l|l|}
\hline Growth on blood culture & Frequency (\%) \\
\hline Organisms & \\
\hline Acinatobacter & $2(2.5 \%)$ \\
\hline Pseudomonas & $2(2.5 \%)$ \\
\hline CONS & $2(2.5 \%)$ \\
\hline E.coli & $1(1.3 \%)$ \\
\hline Citarobacter & $1(1.3 \%)$ \\
\hline Serratia & $1(1.3 \%)$ \\
\hline Staph. aureus & $1(1.3 \%)$ \\
\hline Staph. epidermidis & $1(1.3 \%)$ \\
\hline
\end{tabular}

\section{DisCUSSION}

The study included preterm babies because preterm babies are more prone to develop invasive bacterial infection. The mean $( \pm \mathrm{SD})$ age of the babies was $23.9( \pm 19.3)$ hours. 
In one study reported that, males have been described to be have two- to five-fold higher likeliness to develop septicemia than females, the nearly $2: 1$ ratio of male to female neonates which is similar to various studies that showed an increase in preponderance among male neonates $[6,7]$.

In our study we found that, among the patients, $49(61.3 \%)$ babies were male and $31(38.8 \%)$ were female. The mean $( \pm \mathrm{SD})$ weight of the babies was $1713.8( \pm 436.0) \mathrm{gm}$ with a range of $500-2750 \mathrm{gm}$. Also, we noticed that, $4(5.0 \%)$ babies were extreme preterm (gestational age <28 weeks), 12(15.0\%) babies were very preterm (gestational age 28 to $<32$ weeks) and $64(80.0 \%)$ babies were preterm (gestational age 32 to $<37$ weeks).

In other article it was reported that, $57 \%$ babies birth weight was $<2500 \mathrm{~g}$. In our study we noticed that, among the organisms Acinatobacter were present in $2(2.5 \%)$ patients, Pseudomonas were present in $2(2.5 \%)$, CONS were present in $22.5 \%)$, Citarobacter in $1(1.3 \%)$ patient. Where as in other study reported that, Klebsiella species were the most frequent causative organisms of neonatal sepsis, a similar finding was observed in other study $[5,6]$. In contrast, another study conducted in the neonatal nurseries showed CONS as a major isolate [7]. The variation in the major isolate could be due to differences in study setting, study population and adherence to hand hygiene practices.

\section{CONCLUSION}

From our study we can say that, Acinatobacter, Pseudomonas and CONS were the most common isolate in our study. Early diagnosis and therapy are essential for the prevention of morbidity and mortality of neonatal sepsis in the neonatal intensive care unit.

\section{REFERENCES}

1. Paolucci M, Landini MP, Sambri V. How can the microbiologist help in diagnosing neonatal sepsis?. International journal of pediatrics. 2012 Jan 26;2012

2. NNPD Network. National Neonatal-Perinatal Database - Report 2002-2003. National Neonatology Forum NNPD Network; New Delhi, India.

3. UNICEF, WHO, The World Bank, and The United Nations. Levels and Trends in Child Mortality Report 2011. UNICEF; New York, NY: 2011

4. Qazi SA, Stoll BJ. Neonatal sepsis: a major global public health challenge. The Pediatric infectious disease journal. 2009 Jan 1;28(1):S1-2.

5. Dannstadt GL. Clinical and Bacteriological Profile of Neonatal Septicemia in a Tertiary level Pediatric Hospital in Bangladesh. Indian Pediatrics. 2002;39(1):134-9.

6. Dawodu A, Al Umran K, Twum-Danso K. A case control study of neonatal sepsis: experience from Saudi Arabia. Journal of tropical pediatrics. 1997 Apr 1;43(2):84-8.

7. Jain NK, Jain VM, Maheshwari S. Clinical profile of neonatal sepsis. Kathmandu University medical journal (KUMJ). 2003;1(2):117-20. 